\title{
Advanced Papillary Carcinoma of the Breast Presenting as an Ulcerated Anterior Chest Wall Tumour: Case Report
}

\author{
U. Abubakar ${ }^{1 *}$, J. N. Legbo ${ }^{2}$, S. M. Sahabi ${ }^{3}$, C. Opara ${ }^{2}$, I. R. Jamalu ${ }^{1}$, N. Musa ${ }^{1}$, S. Aliyu ${ }^{3}$ \\ ${ }^{1}$ Cardiothoracic Surgery Unit, Department of Surgery, Usmanu Danfodiyo University Teaching Hospital, Sokoto, Nigeria \\ ${ }^{2}$ Plastic Surgery Unit, Department of Surgery, Usmanu Danfodiyo University Teaching Hospital, Sokoto, Nigeria \\ ${ }^{3}$ Histopathology Department, Usmanu Danfodiyo University Teaching Hospital, Sokoto, Nigeria \\ Email: *drzuru@yahoo.com
}

Received July 20, 2013; revised August 20, 2013; accepted August 28, 2013

Copyright (C) 2014 U. Abubakar et al. This is an open access article distributed under the Creative Commons Attribution License, which permits unrestricted use, distribution, and reproduction in any medium, provided the original work is properly cited. In accordance of the Creative Commons Attribution License all Copyrights (c) 2014 are reserved for SCIRP and the owner of the intellectual property U. Abubakar et al. All Copyright (C) 2014 are guarded by law and by SCIRP as a guardian.

\begin{abstract}
BACKGROUND: Papillary carcinoma of the breast is a rare malignant tumour accounting for $1 \%-2 \%$ of all breast cancers in women. Papillary carcinomas of the chest wall are always secondary to thyroid, thymus and ovaries. Other variants of breast cancer metastasizing to the chest wall have been reported. CASE: We report a 67-year-old woman presented to us with an ulcerated anterior chest wall mass of 1-year duration, bilateral axillary, supraclavicular and cervical swellings of 8-month duration. There was a history of breast lump which was noticed 5 years prior to presentation, no history of breast malignancy in the past and no family history of breast cancer. Examination revealed an ulcerated, nodular mass over the sternal angle which measured $14 \mathrm{~cm} \times 12 \mathrm{~cm}$ $\times 4 \mathrm{~cm}$; she had bilateral axillary, supraclavicular and cervical lymphadenopathy which were non-tender and matted. She had a firm, non-tender right breast lump measuring $6 \mathrm{~cm} \times 4 \mathrm{~cm}$. Chest examination and abdominal examinations were essentially normal. Chest $X$-ray revealed erosion of sternal bone without any evidence of intrathoracic extension. Abdominal ultrasound and thyroid scans were normal. Histology of the mass revealed papillary carcinoma. Biopsy of the right breast also revealed papillary carcinoma. She had excision of the fungating tumour and primary closure of defect. She subsequently had combination chemotherapy using ondasetron, cyclophosphamide, adriamycin and cisplantin. CONCLUSION: Papillary carcinoma of the breast is rare and rarely metastasizes to the chest wall. The diagnosis of metastatic chest wall tumour requires meticulous history taking, clinical examination and relevant investigations to ascertain the primary origin of the carcinoma.
\end{abstract}

\section{KEYWORDS}

\section{Advanced Papillary Carcinoma; Chest Wall Tumour; Breast Carcinoma; Ulcerated Tumour}

\section{Introduction}

Papillary carcinoma of the breast is a rare malignant tumour accounting for $1 \%-2 \%$ of all breast cancers in women. It occurs in older women aged 63 - 67 years [1]. Histologically, papillary carcinoma may be intraductal or intracystic and each type can be non-invasive or invasive, a distinction possible only on thorough histopathological examination. The intracystic variant of papillary carcinoma is very uncommon with only a few cases reported in the available literature. Unlike invasive ductal carcinoma and NOS type, the prognosis of papillary carcino-

\footnotetext{
*Corresponding author.
}

ma is extremely good, even in tumors showing stromal invasion [2]. Papillary cancers of the chest wall are almost always secondary [3-6].

We report a case of advanced papillary carcinoma of the breast presenting as an anterior chest wall mass.

\section{Case}

A 67-year-old woman presented to us with an ulcerated anterior chest wall mass of 1 year duration, bilateral axillary, supraclavicular and cervical swellings of 8 months duration. No preceding history of trauma and denied history of breast lump. No history of breast malignancy in 
the past and no family history of breast cancer. Examination revealed an ulcerated, nodular mass over the sternal angle which measured $14 \mathrm{~cm} \times 12 \mathrm{~cm} \times 4 \mathrm{~cm}$; (see Figure 1), she had bilateral axillary, supraclavicular and cervical lymphadenopathy which were non-tender and matted. Chest examination and abdominal examinations were essentially normal.

Chest X-ray revealed erosion of sternal bone without any evidence of intrathoracic extension and no mediastinal widening. Abdominal ultrasound and thyroid scans were normal. Histology of the mass revealed papillary carcinoma (see Figure 2). Biopsy of the axillary tail mass also revealed papillary carcinoma (see Figure 3)

She had excision of the fungating tumour and primary closure of defect (see Figures 4 and 5). She subsequently had combination chemotherapy using ondasetron, cyclophosphamide, adriamycin and cisplantin.

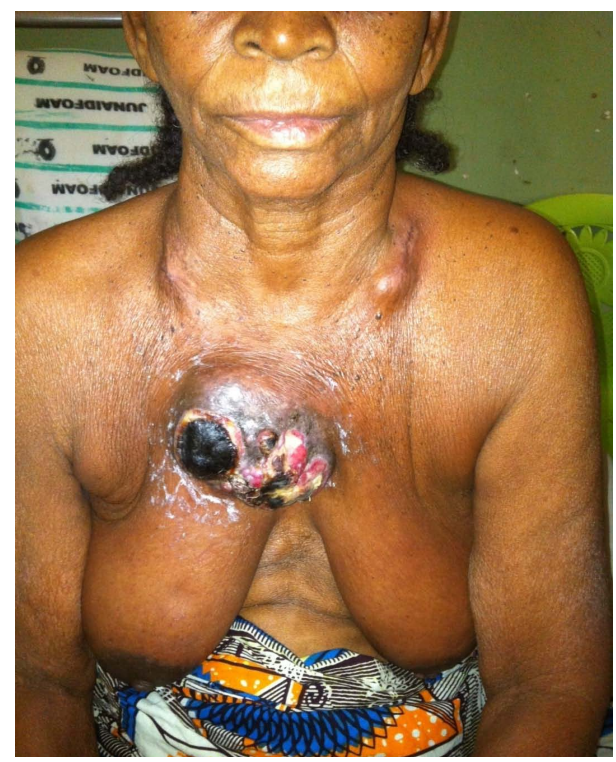

Figure 1. Pre-operative photograph.

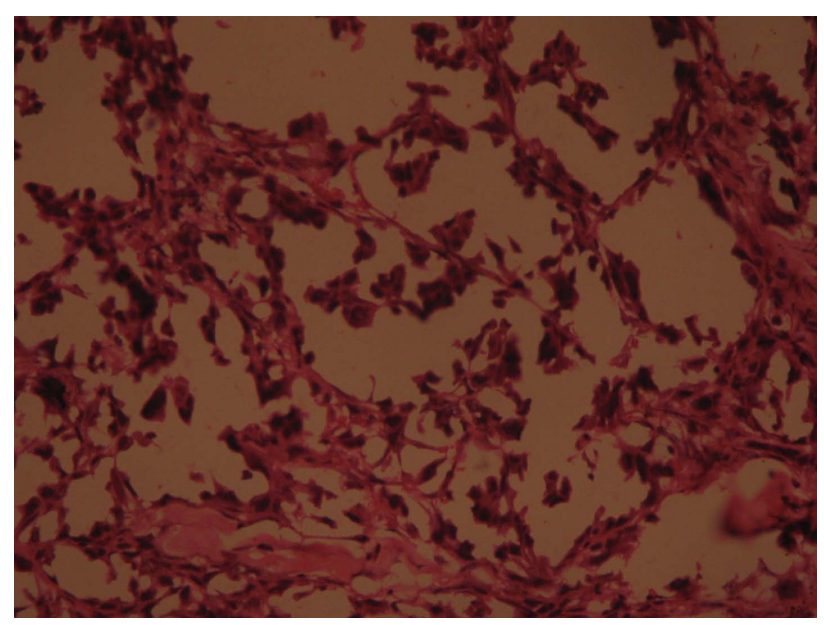

Figure 2. Photomicrograph 1 (chest wall mass).

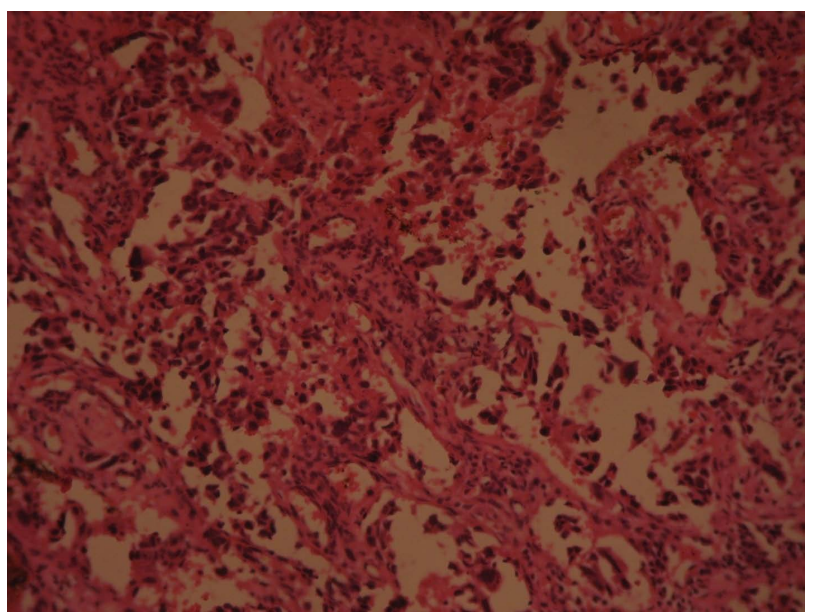

Figure 3. Photomicrograph-tumour from right breast.

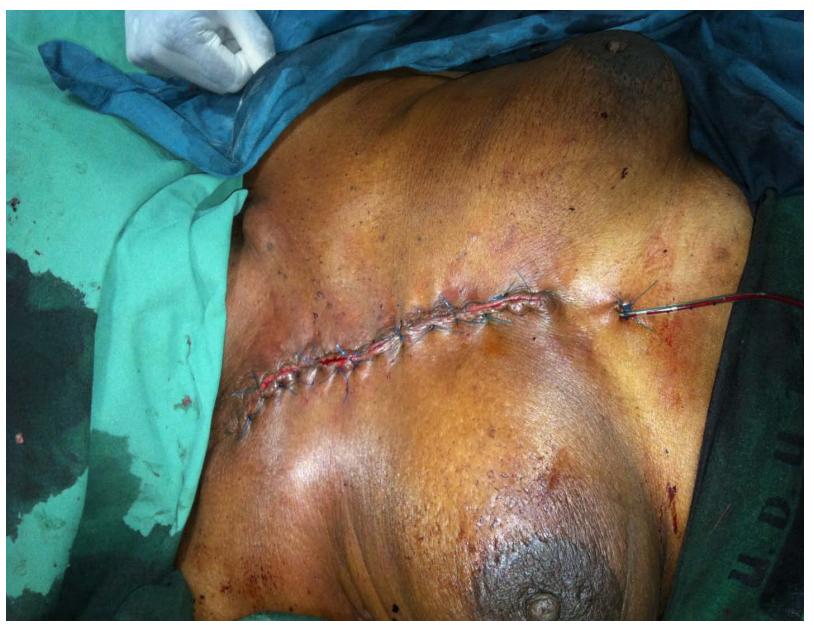

Figure 4. Immediate post-operative photograph.

\section{Discussion}

Primary tumors of the chest wall are uncommon. Of 2000 primary bone tumors in a series at the Mayo Clinic reported by Pascuzzi and colleagues [7] in 1957, only $126(6 \%)$ occurred in the ribs and $18(1 \%)$ were in the sternum.

Nearly half of all chest wall tumors originate in cartilage. Metastatic malignancy must always be considered when a patient presents with a chest wall tumor, particularly if multiple sites of involvement are noted. Malignancies of the breast or lung can involve the chest wall by direct extension as well as by the metastatic route. Other tumors likely to metastasize to ribs and sternum include those arising in the kidney or prostate. A renal or thyroid malignant tumor in the sternum may even mimic aortic aneurysm by presenting as a pulsatile mass tissue [8].

Papillary carcinomas are rare malignant breast tumors, constituting $1 \%-2 \%$ of breast carcinomas in women $[1,9]$. This carcinoma has also been reported in male 


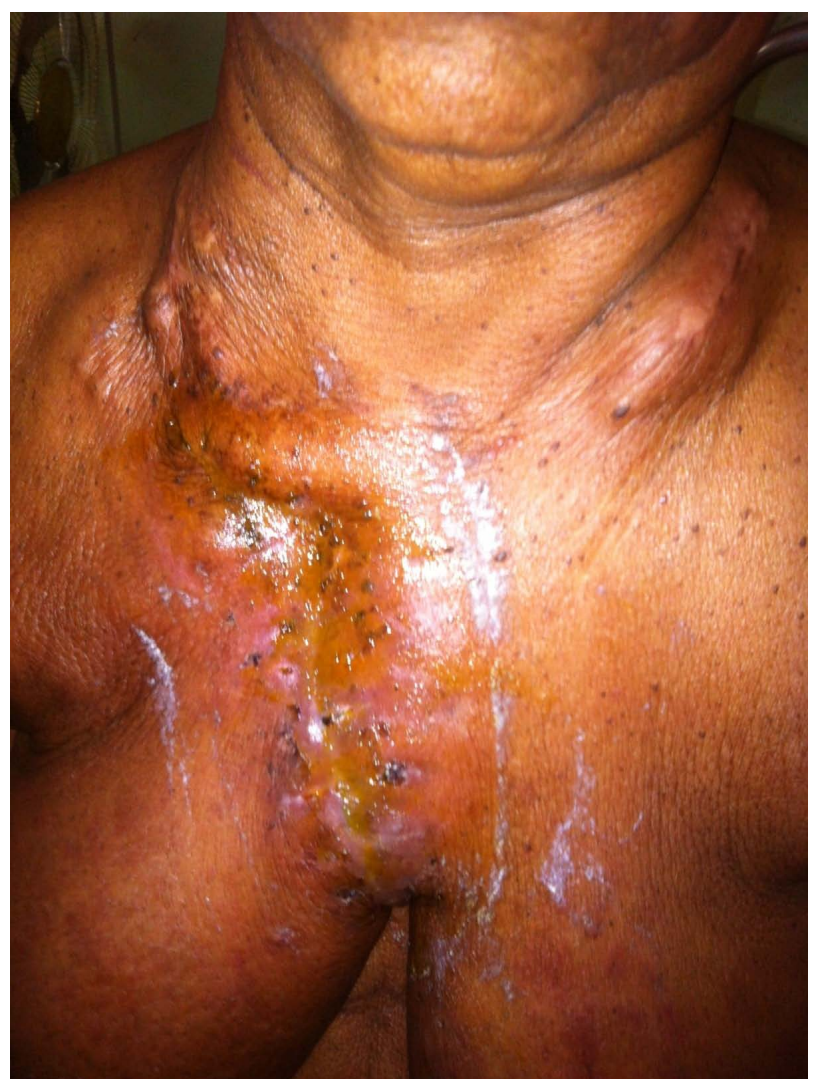

Figure 5. Post-operative photograph before discharge from the hospital.

breast cancer $[10,11]$. Generally characterized by slow growth and a better prognosis than ductal carcinomas not otherwise specified, papillary carcinomas may have in situ (intracystic or intraductal) or invasive components. Intracystic papillary carcinoma can occur in a pure form, or it may be associated with ductal carcinoma in situ or invasive carcinoma not otherwise specified [12].

Papillary carcinomas metastasizing to the chest wall are usually from the thyroid, ovaries and thymus. There are few reports of papillary carcinoma of the breast metastasizing to the chest wall. Our patient presented with an obvious anterior chest wall mass which we initially thought was a primary chest wall tumour until we saw the histology report. This prompted us to pursue the primary, breast examination revealed a mass measuring 4 $\mathrm{cm} \times 2 \mathrm{~cm} \times 1 \mathrm{~cm}$ in the right breast. Histology of which turned out to be papillary carcinoma. Our patient presented with advanced disease as such the option of curative surgery was not considered but instead she had excision of the fungating mass which had foul-smelling discharge and contact bleeding. Primary closure of the defect was achieved. This was done to improve the quality of life. A PET scan was not done for her due to the fact that it is not available in our centre. This would have ascertained the extent of the disease.

\section{Conclusion}

Papillary carcinoma of the breast is rare and rarely metastasizes to the chest wall. The diagnosis of metastatic chest wall tumour requires meticulous history taking, clinical examination and relevant investigations to ascertain the primary origin of the carcinoma.

\section{REFERENCES}

[1] M. Muttarak, A. Somwangprasert and B. Chaiwum, "Intracystic Papillary Carcinoma of the Breast," Biomedical Imaging and Intervention Journal, Vol. 1, No. 1, 2005, p. e5. http://dx.doi.org/10.2349/biij.1.1.e5

[2] R. Arora, R. Gupta, A. Sharma, et al., "Invasive Papillary Carcinoma of Male Breast,” Indian Journal of Pathology and Microbiology, Vol. 53, No. 1, 2010, pp. 135-137. http://dx.doi.org/10.4103/0377-4929.59206

[3] Y. A. Karamustafaoglu and Y. A. Yoruk, "Chest Wall Distant Metastases of Thyroid Carcinoma,” Trakya Üniversitesi Tıp Fakültesi Dergisi, Vol. 26, No. 4, 2009, pp. 338-341.

[4] J. Krishnamurthy and K. N. Divya, "The Cytology of Subcutaneous Chest Wall Metastasis Originating from Bronchiolo-Alveolar Carcinoma,” Iranian Journal of Pathology, Vol. 6, No. 4, 2011, pp. 212-215.

[5] F. Antonia, N. Rosete, F. Diva, et al., "Papillary Adenocarcinoma of the Thymus: Case Report and Review of the Literature,” International Journal of Surgical Pathology, Vol. 18, No. 6, 2010, pp. 530-533.

[6] S. H. Yil, S. C. Ho and H. B. Joong, "Chest Wall Metastasis from Unknown Primary Site of Hepatocellular Carcinoma," World Journal of Gastroenterology, Vol. 12, No. 13, 2006, pp. 2139-2142.

[7] C. A. Pascuzzi, D. C. Dahlin and O. T. Clagett, "Primary tumors of the Ribs and Sternum,” Surgery, Gynecology \& Obstetics, Vol. 104, No. 4, 1957, pp. 309-400.

[8] B. A. Ozuslu, G. Onur, G. Sedat, et al., "Chest Wall Tumour," Asian Cardiovascular and Thoracic Annals, Vol. 6, No. 3, 1998, pp. 212-215. http://dx.doi.org/10.1177/021849239800600314

[9] D. Carter, S. L. Orr and M. J. Merino, "Intracystic Papillary Carcinoma of the Breast. After Mastectomy, Radiotherapy or Excisional Biopsy Alone,” Cancer, Vol. 52, No. 1, 1983, pp. 14-19.

http://dx.doi.org/10.1002/1097-0142(19830701)52:1<14:: AID-CNCR2820520104>3.0.CO;2-N

[10] R. Laszlo Jr, M. Emmet O’Brien and R. Norma, “Intracystic Papillary Carcinoma in a Male as a Rare Presentation of Breast Cancer: A Case Report and Literature Review,” Journal of Medical Case Reports, Vol. 3, 2009, p. 13. http://dx.doi.org/10.1186/1752-1947-3-13

[11] Y. Miwa, M. Yukako and Y. Sohei, "Intracystic Invasive Papillary Carcinoma of the Male Breast with Analyses of Loss of Heterozygousity on Chromosome 16q," Breast Cancer, Vol. 17, No. 2, 2010, pp. 146-159. http://dx.doi.org/10.1007/s12282-009-0101-4 
[12] A. E. Wagner, P. M. Lavinia and J. W. Gary, "Intracystic Papillary Carcinoma of the Breast with Invasion,” AJR, Vol. 183, No. 5, 2004, p. 1516. 